EESTI NSV TEADUSTE AKADEEMIA TOIMETISED. 21. KOIDE KEEMIA * GEOLOOGIA. 1972, NR. 1

ИЗВЕСТИЯ АКАДЕМИИ НАУК ЭСТОНСКОИ ССР. ТОМ 21 ХИмИЯ * ІЕОЛОГИЯ 1972, № 1

\title{
ПРИМЕНЕНИЕ КОМПЛЕКСООБРАЗОВАНИЯ С МОЧЕВИНОЙ ДЛЯ КАЧЕСТВЕННОГО ОПРЕДЕЛЕНИЯ ДИМЕТИЛОВЫХ ЭФИРОВ ДИКАРБОНОВЫХ КИСЛОТ ИЗОСТРОЕНИЯ МЕТОДОМ ТОНКОСЛОЙНОЙ ХРОМАТОГРАФИИ
}

В литературе имеются немногочисленные сообщения о работах по раз делению эфиров насыщенных дикарбоновых кислот методом адсорбционной тонкослойной хроматографии ['], при рассмотрении которых становится очевидной трудность разделения эфиров дикарбоновых кислот, отличающихся длиной или строением углеводородной цепи [1.2 ${ }^{1}$.

В настоящей статье излагаются результаты разработки метода отделения диметиловых эфиров дикарбоновых кислот (ДМЭ ДКК) нормального строения от изомерных соединений комплексообразованием с мочевиной на хроматографической пластинке.

ДМЭ ДКК являются липофильными полярными соединениями и для их хроматографирования в тонком слое пригодны достаточно активные сорбенты. В настоящем исследовании использовался силикагель КСК. размером зерен $0,06-0,08$ мм и содержанием влаги $5 \%$, обработанный по методике А. Ахрем и А. Кузнецовой [3].

Применяемые растворители - ацетон, пиридин, хлороформ, хлори стый метилен, диэтиловый эфир, бензол, гептан и гексан - перегонялись дефлегматором. Эталонные соединения (ДМЭ ДКК $\mathrm{C}_{4}-\mathrm{C}_{10}$ ) были получены метилированием диазометаном индивидуальных дикарбоновых кислот. Кислоты получались перекрнсталлизацией продажных препаратов, и чистота их составляла 98,3-100\%. Работа проводилась с фракциями ДМЭ ДКК, содержащими компоненты нормального строения и изомеры. Анализ фракций был выполнен газохроматографическим методом по внутреннему стандарту на колонке, заполненной хромосорбом W и апиезоном $L$. Характеристика фракций представлена в табл. 1.

Анализ проводился на пластинках $80 \times 200$ мм с толщиной слоя сорбента 0,5 мм. Хроматографирование осуществлялось в восходящем токе растворителя. В качестве проявителя использовались пары иода.

Из многочисленных систем растворителей с различной элюирующей способностью смесь гексан-эфир $(1: 1)$ была выбрана как наиболее эффективная. В табл. 2 приведены среднне значения $R_{f}$ ДМЭ ДКК в системе гексан-эфир $(1: 1)$, найденные из трех определений.

Сопоставление значений $R_{f}$ из табл. 2 показывает неудовлетворительноє деление в гомологическом ряду ДМЭ ДКК $\mathrm{C}_{4}-\mathrm{C}_{10}$ нормального строения. В виде одного пятна проявлялись также пары компонентов нормального строения и их изомеров. 
Представлялось целесообразным отделение соединений изостроения от прямоцепочных ДМЭ ДКК на хроматографнческой пластинке путем связывания последних в комплекс с мочевиной. Существование соединений включения с мочевиной, образуемых рядом ДМЭ ДКК $\mathrm{C}_{4}-\mathrm{C}_{10}$ нормаль-

Таблица 1

Характеристика исследуемых фракций дМэ дКК

\begin{tabular}{c|l|c}
\hline Фракция & \multicolumn{1}{c|}{ Компонент } & $\begin{array}{c}\text { Содержа- } \\
\text { ние, \% }\end{array}$ \\
\hline \multirow{2}{*}{1} & ДМЭ янтарной кислоты & 96,0 \\
& ДМЭ метилянтарной кислоты & 4,0 \\
\multirow{2}{*}{2} & ДМЭ глутаровой кислоты & 94,0 \\
& ДМЭ $\alpha$-метилглутаровсй кислоты & 5,9 \\
\multirow{2}{*}{3} & ДМЭ адипиновой кислоты & 92,0 \\
\multirow{2}{*}{4} & ДМЭ $\alpha$-метиладипиновой кислоты & 6,0 \\
& ДМЭ пимелиновой кислоты & 94,1 \\
\multirow{2}{*}{5} & ДМЭ $\alpha$-метилпимелнновсй кислоты & 4,3 \\
& ДМЭ пробковой кислоты & 88,5 \\
& ДМЭ $\alpha$-метилпробковой кнслоты & 4,1
\end{tabular}

ного строения, было доказано ранее [4, 5]. Нами было установлено, что метилизомеры ДМЭ ДКК не образуют соединений включения с мочевиной []. Для связывания ДМЭ ДКК нормального строения в комплекс на хроматографической пластинке были опробованы следующие методы.

1. Добавление мочевины к силикагелю.

2. Нанесение метанольного раствора исследуемого эфира и мочевины на пластинку и высушивание перед хроматографированием.

3. Хроматографирование насыщенным метанольным раствором мочевины после нанесения пробы исследуемых эфиров.

Перьым способом в опытах с $10 \%$-ным содержанием мочевины в силикагеле не было достигнуто отделения нормальных компонентов. Это, по-видимому, объясняется тем, что за короткое время хроматографиро вания концентрация мочевины в метаноле в результате растворения не достигала величины, достаточной для образования соединений включе. ния в момент кристаллизации. Дальнейшее увеличение концентрации мочевины в силикагелевом слое и полная замена силикагеля мочевиной, ка́к рекомендует Э. Шталь [7], не имели смысла, так как при хроматографировании метанолом происходит растворение мочевины и нарушение однородности слоя.

При применении второго способа (соотношения исследуемых ДМӘ ДКК и мочевины указаны в табл. 3) более полное связывание эфиров нормального строения на старте было отмечено во II и III сериях опытов. Поэтому оптималыными можно было считать молярные соотношения эфиров с мочевиной во II серии опытов (табл. 3).

Недостаток этого способа - длительность подготовки пробы для анализа и трудность нанесения горячего насыщенного метанольного раствора эфир-мочевина на пластинку в определенных дозах.

Наиболее удобным оказался третий способ при условии предварительного хроматографирования $7 \%$-ным раствором мочевины в метаноле на $1 / 3$ длины пластинки и последующего высушивания. Изменением вели . чины дозы в пределах 6,2-230 мка ILMЭ адипиновой кислоты и фракции ДМЭ адипиновой кислоты с примесью изомера было найдено, тто 
Значения $R_{f}$ ДМЭ ДКК С $-\mathrm{C}_{10}$, полученные в системе растворителей гексанэфир (1:1)

\begin{tabular}{l|l}
\hline Соединение & $\begin{array}{l}\text { Среднее } \\
\text { значение }\end{array}$ \\
\hline
\end{tabular}

ДМЭ янтарной кнслоты

ДМЭ глутаровой кислоты

ДМЭ адипнновой кислоты

ДМЭ пимелиновой кислоты

ДМЭ пробковой кислоты

Д.Э азелаиновой кислоты

ДМЭ себациновой кислоты
0,64
0,66
0,67
0,68
0,72
0,76
0,78
Соотношения ДМә ДКК и мочевины для разделения эфиров нормального и изостроения тонкослойной хроматографией

\begin{tabular}{c|c|c|c}
\hline \multirow{2}{*}{$\begin{array}{c}\text { Соеди- } \\
\text { нение }\end{array}$} & \multicolumn{4}{|l}{ Молярное соотношение ДМЭ } \\
\cline { 2 - 3 } & ДК и мочевины & в опытах \\
\cline { 2 - 5 } & I & II & III \\
\hline
\end{tabular}

$\begin{array}{ccccc}\text { дмЭ } & \mathrm{C}_{4} & 1: 5,7 & 1: 11,4 & 1: 17,1 \\ , " & \mathrm{C}_{5} & 1: 6,5 & 1: 13,0 & 1: 19,5 \\ , & \mathrm{C}_{6} & 1: 7,3 & 1: 14,6 & 1: 21,9 \\ . & \mathrm{C}_{7} & 1: 8,1 & 1: 16,2 & 1: 24,3 \\ , & \mathrm{C}_{8} & 1: 8,8 & 1: 17,6 & 1: 26,4 \\ , & \mathrm{C}_{9} & 1: 9,5 & 1: 19,0 & 1: 19,5 \\ ., & \mathrm{C}_{10} & 1: 10,5 & 1: 21,0 & 1: 31,5\end{array}$

оптимальной язляется доза 200 мкг. При такой дозе после 7 -минутного проявления в парах иода пятно чистого ДМЭ адипиновой кислоты не проявлялось нли проявлялось слабо при удовлетворительном проявленин пятна изомера. На жсновании вышензложенного была принята следую щая методика.

Применялись: пластннка размерами $80 \times 200$ мм, сорбент - силикагель $\mathrm{KCK}(0,06-0,08$ мм) +5\% воды, свидетель - диметиловый эфир

Рис. 1. Хроматограмма ДМЭ ДКК нормального и изостроения. 1 ДМЭ пробковой кислоты, 2 - фрак. ция ДМЭ пробковой кислоты с примесью $\alpha$-метилизомера, 3 - ДМЭ пробковой кислоты $+20 \%$ ДМЭ ฉ-метилпробковой кислоты, 4 ДМЭ $\alpha$-метилпробковой, кислоты.

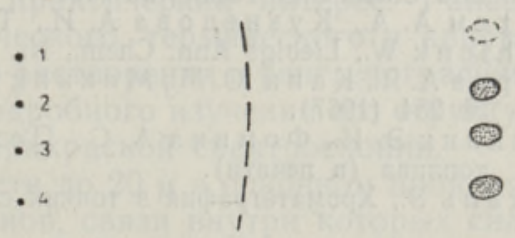

адипиновой кислоты. Доза исследуемого эфира и свидетеля - 200 мкг (3\%-ный раствор в меганоле).

Метанольные растворы свидетеля н нсследуємой смесн наносились на пластинку и хроматографировались метанольным раствором мочевины (концентрация 7 вес. \%) на расстоянии $1 / 3$ длнны пластинки. Метанол полностью удалялся высушиванием на воздухе в течение 15 мин (в конце допускался слабый подогрев электролампой), затем производилось хроматографирование в системе гексан-эфир (1:1). Время хроматографирования 20 мин. Пластинка подсушивалась на воздухе $(1-2$ мин) и проявлялась в парах иода в теченне $5-7$ мин.

При наличии соединений с разветвленной цепью в исследуемой пробе наблюдалось проявление их пятен. Пятно свидетеля при этом не проявлялось или имело более слабую интенсивность.

Минимальное содержание изокомпонента в пробе, обнаруженное предложенным методом, составляло $4--5 \%$. Таким способом был проана. лизирован ряд смесей ДМЭ ДКК нормального и нзостроения - ДМЭ пробковой кислоты, фракция ДМЭ пробковой кислоты с примесью $\alpha$-метилизомера, смеси $80 \%$ ДМЭ пробқовой кислоты и $20 \%$ ДМЭ $\alpha$-ме тилпробковой кислоты и ДМЭ $\alpha$-метилпробковой кислоты. После проявления в течение 5--6 лин обнаружилось 3 пятна. В пробе ДМЭ пробковой кислоты пятно не проявилось. Интенсивность других пятен возрас тала в вышеуказанной последовательности (рис. 1).

При параллельном хроматографнрованин ДМЭ ДКК нормального строения и фракций с изокомпонентами после 3--5-минутного проявле- 


\begin{tabular}{|c|c|}
\hline - $c_{4}$ & $\begin{array}{l}1 \\
1\end{array}$ \\
\hline - $\Phi_{D} C_{2}$ & $\begin{array}{l}1 \\
1\end{array}$ \\
\hline$\cdot c_{5}$ & 1 \\
\hline - $\Phi_{D} C_{5}$ & 1 \\
\hline$\cdot c_{6}$ & 1 \\
\hline - $\Phi_{D} \cdot C_{G}$ & 1 \\
\hline$\cdot C_{7}$ & 1 \\
\hline - $\Phi_{p, C_{7}}$ & 1 \\
\hline - $C_{8}$ & 1 \\
\hline - $\Phi_{D} \cdot C_{8}$ & 1 \\
\hline $\begin{array}{l}\text { - } c_{9} \\
\text { - } \phi_{p} c_{-}-c_{n}\end{array}$ & \\
\hline $\begin{array}{l}\text { - } \Phi_{D} \cdot C_{9}-C_{10} \\
\text { - } C_{10}\end{array}$ & $1=0$ \\
\hline
\end{tabular}

Рис. 2. Хроматограмма фракций ДМЭ ДКК с изокомпонентами и индивидуальных ДМЭ ДКК нормального строення, полученная в результате связывания последних в комплексы с мочевиной.

ния были четко обнаружены пятна фракций, в то время как пятна эфиров нормального строения отсутствовали или проявлялись сла бо. Исключение составляли чистые диметиловые эфиры янтарной и глутаровой кислот и фракции этих эфиров. Удовлетворительная раз ница в проявлении чистых эфиров и фракций с примесями наблюдалась не во всех опытах (рис. 2).

В результате проведенного исследования разработана методика качественного определе ния ДМЭ ДКК изостроения в смесях способом тонкослойной хроматографии на силикагеле с применением комплексообразювания с мочевиной.

\section{ЛИТЕРАТУРА}

1. Br a u n D., Kunststoffe, 52, Nr. 2 (1962).

2. R a nderath K., Dünnschicht-Chromatographie. Monographien zu Angew. Chemie und Chem.-Ingr-Techn., 20 (1962).

3. Ахрем А. А., К узнецов а А. И., Тонкослойная хроматография, М., 1964.

4. S chlen k W., Liebigs Ann. Chem., Nr. 565, 204 (1949).

5. А а рн а А. Я., К а н и Ю. М., М янн и к А. О., Тр. Таллинск. политехн. ин-та, Серия А, № 254 (1967).

6. Мянник Э. И., Фомина А. С., Пехк Т. И, Мянник А. О., Химия твердого топлива (в печати).

7. Ш т а в Э., Хроматография в тонких слоях, М., 1965, с. 174.

Институт химии

Академии наук Эстонской ССР
Поступила в редакцию $16 / \mathrm{V} 11971$

\section{EMILIA MANNIK, A. FOMINA, O. IKONOPISTSEVA}

\section{KARBAMIIDIDE KOMPLEKSIDE KASUTAMINE DIKARBOKSUULHAPETE DIMETUULESTRITE ISOMEERIDE KVALITATIIVSEKS MAXRAMISEKS ADSORBENDI OHUKESES KIHIS KROMATOGRAAFIAMEETODIL}

Isomeersete dikarboksüülhapete dimetüülestrid eraldati normaalsete dikarboksüülhapete dimetuülestritest kompleksi moodustamise teel kromatograafilisel plaadil. Sel meetodil on dikarboksüülhapete dimetüülestrite segudes võimalik määrata 4 vôi enam protsenti isoehitusega dikarboksüülhapete dimetüülestritest.

\section{EMILIA MANNIK, A. FOMINA, O. IKONOPISTSEVA}

\section{ANWENDUNG DES HARNSTOFFS ALS KOMPLEXBILDNER ZUR TRENNUNG GERADEKETTIGER UND VERZWEIGTER DICARBONSÄUREDIMETHYLESTER- ISOMEREN AUF EINER DUNNSCHICHT-CHROMATOGRAPHIE-PLATTE}

Die geradekettigen und verzweigten Dicarbonsäuredimethylester-Isomeren wurden mit Hilfe des Harnstoffs auf einer Dünnschicht-Chromatographie-Platte getrennt.

Es ist möglich, durch dieses Verfahren $4 \%$ und mehr-Isodicarbonsäuredimethylester im Gemisch . zu bestimmen. 